\title{
A posição do adjetivo no sintagma nominal em Português
}

\section{Position of the Adjective in Portuguese Nominal Syntagmata}

\author{
JAN BUĎA [218219@mail.muni.cz] \\ Masarykova univerzita, República Checa
}

\begin{abstract}
RESUMO
A problemática da anteposição e posposição do adjetivo nos sintagmas nominais portugueses é uma questão abordada tradicionalmente com escassa profundidade e com raras tentativas de sistematização, ainda que se trate dum interessante problema linguístico e também didático que merece atenção. Servindo-se dum corpus de linguagem literária, o presente artigo analisa sistematicamente (nos diversos planos linguísticos) os fatores que influem no processo da colocação do adjetivo num sintagma nominal. Os resultados são confrontados com afirmações de várias gramáticas contemporâneas e desenvolvidos com a finalidade de introduzir uma abordagem integral da problemática. A análise do corpus é precedida por uma breve revisão das mencionadas gramáticas e dos seus discursos acerca das classes lexicais de substantivo e adjetivo.
\end{abstract}

\section{Palavras-Chave}

sintagma nominal; colocação; posição do adjetivo; linguística de corpus

\begin{abstract}
The problematic of anteposition and postposition of the adjective in Portuguese nominal syntagmata is a question traditionally approached not very deeply and there have been scarce attempts of systematization, although it presents an interesting linguistic and didactic problem deserving attention. Using a corpus of literary language, the present article systematically (looking at different linguistic fields) analyses the factor influencing the process of the adjectives' collocation inside the nominal syntagma. The results are confronted with the affirmations of several contemporary grammars and elaborated to present an integral approach of the problematic. The analysis of the corpus is preceded by a short revision of the grammars and their discourses about the definition and distinction of noun and adjective in Portuguese.
\end{abstract}

\section{KEYWORDS}

nominal syntagma; Portuguese; adjective collocation; corpus linguistics

RECEBIDO 2016-08-03; ACEITE 2017-01-31 


\section{Introdução}

É normal que na realidade quotidiana das nossas vidas enfrentamos o facto de haver desconformidade entre o que nos foi relatado ou explicado acerca de algum fenómeno e o que realmente percebemos. A problemática da anteposição e posposição do adjetivo nos sintagmas nominais ${ }^{1}$ portugueses é um caso concreto de tal contradição. Esta questão tem sempre sido objeto de considerações linguísticas, dado que a prática do posicionamento é, até certo ponto, percebida como subjetiva e foge constantemente a qualquer sistematização estabelecida dentro de regras gramaticais. As gramáticas contemporâneas, ou digamos "modernas", com raras exceções, infelizmente evitam debruçar-se pormenorizadamente sobre esta problemática. Nesta situação sem remédio, vemo-nos chamados a combater nós próprios o problema e tentar preencher esta lacuna existente no conhecimento da língua portuguesa.

Este artigo tem por objetivo aproximar ao leitor diversas relações (sobretudo sintáticas) entre os substantivos e os adjetivos verificadas no uso prático da língua. Supondo que a linguagem mais culta e mais representativa quanto à pureza lexical, semântica e dialetológica é a linguagem literária, concentrámos o nosso interesse no registo literário português, tanto como brasileiro, preponderantemente em obras escritas nos últimos dois séculos. Como instrumento mais adequado para esta finalidade selecionámos o Corpus do Português. Os dados recolhidos pelas pesquisas no corpus foram por fim avaliados por um lado com recurso a instrumentos básicos da estatística, por outro lado do ponto de vista qualitativo que forneceu muitas revelações interessantes.

Notemos ainda que este artigo foi escrito com observação do Acordo Ortográfico de 1990. Embora não concordemos com grande parte das mudanças efetuadas na ortografia portugue$\mathrm{sa}^{2}$, consideramos inevitável respeitar as regras vigentes e já amplamente adotadas nos textos oficiais e académicos. Quaisquer textos citados, não obstante, serão apresentados com a grafia original do respetivo período histórico e região geográfica.

\section{Enquadramento metodológico}

A análise das gramáticas de português existentes foi um ponto de partida indispensável para o nosso trabalho, uma vez que as gramáticas representam o que já foi relatado ou constatado por autoridades mais competentes. Analisámos portanto várias obras de autores amplamente reconhecidos: Maria Helena Mira Mateus (2003), Pilar Vázquez Cuesta (1989), Evanildo Bechara (2001) e também, marginalmente, do checo Zdeněk Hampl (1972)³. Esta parte teórica consiste numa análise das definições dos termos substantivo e adjetivo e das regras de colocação indicadas por estes autores.

Como foi aludido na introdução, o Corpus do Português (acessível a partir de http://www. corpusdoportugues.org) foi a ferramenta essencial para a nossa pesquisa. Trata-se dum corpus

1 Logo no início enfrentamos um problema terminológico: chamaremos comummente de nomes o conjunto dos substantivos e adjetivos (em conformidade com a divisão tradicional em nomes substantivos e nomes adjetivos), mas distinguiremos os sintagmas nominais (cujo núcleo é sempre um substantivo) e sintagmas adjetivais.

2 A nossa atitude está expressa de forma desenvolvida em Buda (2010).

3 Para os títulos concretos, ver bibliografia. 
criado e administrado pelos linguistas estado-unidenses Mark Davies e Michael J. Ferreira, representando estes respetivamente a Brigham Young University em Utah e a Georgetown University em Washington, e sob apoio do National Endowment for the Humanities (NEH), uma fundação de apoio a pesquisas na área das humanidades ${ }^{4}$. Presentemente, este corpus orgulhase de ser o maior corpus existente de português, contendo cerca de 45 milhões de palavras usadas em 57.000 textos.

A ferramenta foi-nos especialmente útil na parte empírica da pesquisa, na qual trabalhámos com os números de ocorrências dos adjetivos em diferentes posições. Com apoio nos resultados descobrimos relações entre a posição do adjetivo e valores semânticos, fonéticos e sintáticos, que influem na decisão sobre a sua posição. É com recurso a todos estes valores que as palavras em geral (não só substantivos e adjetivos) estabelecem diversas relações entre si e determinam simultaneamente a gramaticalidade de certas ordens e a agramaticalidade de outras.

\section{Análise das gramáticas existentes}

\subsection{Problemática das definições dos nomes}

Uma vez que as duas classes dos nomes são muito próximas tanto a nível morfossintático como semântico, a sua distinção é muitas vezes discutível e as suas definições variam, apoiando-se cada autor em critérios diferentes. Veremos neste capítulo que a definição das classes lexicais é um problema bem complicado.

\subsubsection{Definições do substantivo}

As elaborações da definição do substantivo principalmente partem de dois possíveis pontos de vista - apoiam-se ou nas características sintáticas ou nas semânticas. Uma abordagem sintética ancorada em ambos estes planos linguísticos aparece em Cunha e Cintra (2006: 130), que definem o substantivo por um lado como "a palavra com que designamos ou nomeamos os seres em geral”, enumerando “a) os nomes de pessoas, de lugares, de instituições, de um género, de uma espécie ou de um dos seus representantes: [...] b) os nomes de noções, acções, estados, e qualidades, tomados como seres", mas por outro lado se apoiam no ponto de vista funcional: "o substantivo é a palavra que serve, privativamente, de núcleo de sujeito, do objecto directo, objecto indirecto e do agente da passiva. Toda palavra de outra classe que desempenhe uma dessas funções equivalerá forçosamente a um substantivo (pronome substantivo ${ }^{5}$, numeral ou qualquer palavra substantivada).”

4 Mais informações sobre as organizações referidas podem ser obtidas nas respetivas páginas da Internet: http:// home.byu.edu, http://www.georgetown.edu, http://www.neh.gov.

5 Cunha e Cintra (2006: 200) (de modo semelhante a Vázquez Cuesta 1989) dividem mesmo os pronomes em "pronomes substantivos e pronomes adjectivos", apoiando-se nas suas características morfossintáticas (flexibilidade) e usando paralelamente a divisão clássica em pessoais, possessivos, demonstrativos, relativos, interrogativos, indefinidos e negativos. 
Esta definição tornou-se clássica apesar de apresentar certas lacunas, como a de não incluir explicitamente na classe dos substantivos todas as palavras que não designam "os seres em geral" ou os significados enumerados na letra b) "tomados como seres", isto é palavras como chuva, azar, leite. Estas palavras cabem indubitavelmente na classe dos substantivos, mas podem os seus denotados ser "tomados como seres"?

Bechara (2001: 112) serve-se praticamente de argumentos idênticos de natureza semântica, afirmando que o substantivo "é classe de lexema que se caracteriza por significar o que convencionalmente chamamos objetos substantivos, isto é, em primeiro lugar, substâncias (homem, casa, livro) e, em segundo lugar, quaisquer outros objetos mentalmente apreendidos como substâncias, quais sejam qualidades (bondade, brancura), estados (saúde, doença), processos (chegada, entrega, aceitação)”. Já acima constatámos que uma definição através da enumeração de possíveis significados é insuficiente, porque a soma de todos os significados que os substantivos podem adquirir não é um conjunto finito. O conceito dos "objetos mentalmente apreendidos como substâncias" é igualmente problemático como o dos "nomes tomados como seres".

Já Mateus et alii (1987) resolve este problema evitando completamente o termo "substantivo" e, consciente das dificuldades acima referidas, substitui-o por "nominal". Os nominais, afirma, "são categorias linguísticas caracterizáveis semanticamente por terem um potencial de referência, i.e., por serem, em geral, utilizados numa situação concreta de comunicação, com uma função designatória ou de nomeação; [...] podem designar uma gama de entidades cuja consideração (ou construção) envolve, do ponto de vista cognitivo, diferentes graus de abstracção e complexidade conceptual.” Esta definição é praticamente livre de lacunas, mas é tão exigente em termos de compreensão que qualquer mortal evitará usá-la na prática.

Dos factos assinalados concluímos então que o maior problema das definições é a inclusão de substantivos abstratos, sem referente de natureza física. A abordagem tradicional de Bechara (2001) e Cunha e Cintra (2006) sobrevaloriza o lado semântico dos substantivos, pouco considerando o seu emprego sintático e omitindo inteiramente os processos comunicativos que estão por trás do seu uso. Mateus et alii (2003) tenta evitar estas lacunas em detrimento de um altíssimo grau de abstração.

\subsubsection{Definições do adjetivo}

Surpreendentemente, Hampl (1972), Vázquez Cuesta (1989) e Mateus et alii (2003)6 evitam definir o termo «adjetivo» de qualquer modo. Restam portanto para consulta as gramáticas de Cunha e Cintra (2006) e Bechara (2001).

A famosa gramática de Cunha e Cintra (2006: 181) diz em respeito à definição do adjetivo que «é essencialmente um modificador do substantivo» e que serve:

6 Para a defesa de Mateus et alii (2003) digamos que esta gramática tenta evitar a divisão tradicional em classes lexicais, o que a leva a formulações e discursos mais acertados, mas menos compreensíveis e menos acessíveis ao público. 
(1) para caracterizar os seres, os objectos ou as noções nomeadas pelo substantivo, indicandolhes: a) uma qualidade (ou defeito) [...], b) o modo de ser [...], c) o aspecto ou aparência [...], d) o estado [...].

(2) para estabelecer com o substantivo uma relação de tempo, de espaço, de matéria, de finalidade, de propriedade, de procedência, etc. (adjectivo de relação) [...].

Em rigor, esta definição omite certos adjetivos, como p. ex. falso, suposto, existente, extremo, que caem fora desta definição, se bem pertençam à classe dos adjetivos.

A definição de Bechara (2001: 142) limita-se a afirmar que o "adjetivo é a classe de lexema que se caracteriza por constituir a delimitação, isto é, por caracterizar as possibilidades designativas do substantivo, orientando delimitativamente a referência a uma parte ou a um aspecto do denotado." Esta definição, com alicerces na semântica, reabre o problema da distinção dos adjetivos e substantivos. Uma vez aberta, esta definição não tem suficiente capacidade delimitadora para poder delimitar claramente o termo em questão. Confirma-se pelo dito que a definição e distinção dos nomes portugueses tem que ser efetuada a partir de critérios sintáticos, porque no campo semântico os domínios das duas classes parcialmente se sobrepõem. Também no campo sintático existem áreas de litígio; em comparação com o campo semântico são porém mínimas.

Considerando as dificuldades expostas acima e certas limitações impostas pelo corpus usado, usaremos na nossa pesquisa um conceito bastante vasto do termo adjetivo: incluiremos também certas unidades lexicais que tipicamente desempenham a função de quantificadores e determinantes e que, de forma ora estável ora não, são classificadas como pronomes. ${ }^{7}$ Dado que a avaliação estatística será efetuada por unidade lexical (sem deduzir valores relativos ao conjunto inteiro dessas unidades), não corremos qualquer risco de degradação do resultado. Igualmente serão incluídas formas sintéticas comparativas e superlativas - estas formas, sendo sintéticas, são portadoras de algumas características (prosódicas, fonéticas, fraseológicas) diferentes da forma positiva que podem merecer atenção; e seria, finalmente, extremamente difícil retirar dos resultados formas comparativas e superlativas dos adjetivos com gradação analítica.

\subsection{Problemática da colocação do adjetivo}

Quanto à colocação do adjetivo, as gramáticas oferecem, ao lado de alguns factos conhecidos e tidos por óbvios, ${ }^{8}$ uma surpreendente variedade de outras abordagens, das quais extrairemos agora os pontos mais originais e interessantes.

7 O corpus realmente trabalha com uma ideia muito abrangente da classe do adjetivo, incluindo além de numerais ordinais também particípios e pronomes possessivos, deíticos e indefinidos. Filtrámos os resultados para remover unidades lexicais que obviamente fogem ao entendimento geral do termo "adjetivo", guardando aliás certas unidades de classificação discutível ou oscilante.

8 As gramáticas principalmente acordam que a anteposição pode exprimir certo grau de figuração, modificar o significado do adjetivo, proporcionar-lhe um valor intrínseco ou fortificado. 
O primeiro tipo de abordagem poderia ser chamado de taxativo ou enumerativo. De bom exemplo servirá Zdeněk Hampl (1972), o pioneiro checoslovaco da linguística lusitana, que divide os adjetivos antepostos em dois grupos. O primeiro inclui adjetivos, cujo significado não é modificado através da anteposição, como bom, chamado, delicado, devido, eminente, enorme, excelente, expressivo, famoso, igual, ilustre, inúmero, ligeiro, longo, mau, numeroso, pequeno, presente, saudoso, semelhante, último, útil, velho; o segundo grupo é constituído por aqueles que mudam de significado conforme a sua posição, como antigo, bravo, caro, diverso, franco, grande, leve, maior, menor, novo, pobre, próprio, puro, simples, verdadeiro, verde.

Permitimo-nos aqui observar que a obra de Hampl, embora pioneira e de extrema importância para o ensino de português na Checoslováquia, apresenta certas informações de forma um tanto enganosa. Entre os adjetivos enumerados há alguns que chamaram a nossa atenção quanto à afirmação que "é regra serem antepostos". Para verificar esta afirmação introduzimos estes adjetivos no corpus da ficção e organizámos os resultados numa tabela:

\begin{tabular}{|l|r|r|}
\hline \multicolumn{1}{|c|}{ Adjetivo } & Anteposições & Posposições \\
\hline expressivo & 13 & 24 \\
\hline igual & 116 & 138 \\
\hline útil & 6 & 35 \\
\hline saudoso & 34 & 20 \\
\hline
\end{tabular}

Vemos que não é tão fixa a regra de estes adjetivos serem antepostos, em 3 dos 4 casos é até o contrário. Não obstante, a abordagem de Hampl, graças à sua simplicidade, tornou-se um método de tratar a problemática colocacional no ensino de português como língua estrangeira, sobretudo ao nível básico.

Vázquez Cuesta (1989) aborda a problemática de forma semelhante, mas acrescenta um conceito que despertou o nosso interesse. Afirma concretamente que "o adjetivo anteposto perde um pouco do seu valor e tende a formar com o substantivo grupos fraseológicos tópicos. Dizse, por exemplo, as doiradas espigas, sem que as espigas sejam sempre doiradas, porque se admitiu um dia que deviam sê-lo, e o inspirado artista, o sábio Professor, atribuindo a um caso concreto qualidades inerentes ao substantivo absoluto e abstracto.”

A autora suscita uma ideia interessante que tentaremos desenvolver mais adiante: os adjetivos antepostos tendem a formar grupos fraseológicos tópicos, ou seja, combinações específicas de substantivos e adjetivos, estabelecidas e «consagradas pelo uso», nas quais o adjetivo costuma ser anteposto. Nestas combinações, os significados originais dos nomes podem sofrer uma leve modificação mútua. ${ }^{9}$

Só a consulta de Mateus et alii (2003) introduz uma verdadeira sistematização na problemática da colocação. As autoras dividem os adjetivos em cinco subcategorias. As primeiras duas categorias, as mais importantes, são formadas pelos adjetivos modificadores ou qualificativos ${ }^{10}$

9 Trata-se dum fenómeno próximo das "expressões idiomáticas", as quais geralmente apresentam um grau mais elevado de transformação dos denotados.

10 Mateus et alii (2003: 377-378), capítulo 11.3.2. Tipos de adjectivos. 
e pelos adjetivos relacionais. Enquanto estes últimos servem para restringir ou limitar o denotado do substantivo, os primeiros designam as suas qualidades e não interferem com o seu denotado. Isto proporciona aos adjetivos qualificativos várias outras características, como a graduabilidade, o direito à posição predicativa e, finalmente, o direito à anteposição aos substantivos. Os adjetivos relacionais geralmente carecem destas características. Compare-se:

- qualificativo: uma casa alta; uma casa muito alta; uma alta casa; a casa é (bastante) alta.

- relacional: um romance policial; ${ }^{\star}$ um romance muito policial; ${ }^{\star}$ um policial romance; $\left({ }^{*}\right)$ o romance é policial. ${ }^{11}$

Além desta classificação principal na qual cabe a maioria dos adjetivos, Mateus et alii (2003) distingue ainda outras três subcategorias, cada uma representada por poucas dezenas de unidades lexicais: são os adjetivos "modificadores do significado ou intensão dos nomes" 12 como principal, mero, pleno, único, adjetivos "negativos e conjeturais" como falso, presumível, suposto, presente e adjetivos "modais e temporais-aspectuais" como possível, provável e frequente, permanente, súbito. Como antecipámos, a necessidade dos falantes de modificar a polaridade, intensão, o significado, modo e aspeto temporal dos substantivos, entre outros componentes da perceção humana da realidade, não é nada menor que a necessidade de caracterizá-los e restringir-lhes o denotado. Dado o número limitado destes adjetivos, a frequência do seu uso é correspondentemente alta. A seguinte tabela resume as diferenças essenciais entre as subcategorias de adjetivos, tal como expostas por Mateus et alii (2003):

\begin{tabular}{|l|c|c|c|c|}
\hline Classe & Anteposição & Posposição & Graduabilidade & $\begin{array}{c}\text { Posição } \\
\text { predicativa }\end{array}$ \\
\hline modificadores ou qualificativos & possível & normal & sim & possível \\
\hline relacionais & impossível & regra & não & impossível \\
\hline $\begin{array}{l}\text { modificadores de significado } \\
\text { ou intensão dos nomes }\end{array}$ & regra & excecional & não & impossível \\
\hline negativos e conjeturais & regra & excecional & não & impossível \\
\hline modais e temporais-aspetuais & normal & possível & sim & possível \\
\hline
\end{tabular}

Na gramática de Bechara (2001) não há muitas informações substanciais sobre a colocação do adjetivo, mas este autor apresenta vários pensamentos originais. Ele realça as possíveis influências fonéticas ( «rítmicas») e psicológicas na ordem em geral, ideia que também defendemos e quanto sabemos, não se repete nas outras gramáticas estudadas. ${ }^{13}$ Essa vertente pode ser bem exemplificada com o seguinte excerto da gramática: "A colocação, dentro de um idioma, obedece a tendências variadas, quer de ordem estritamente gramatical, quer de ordem rítmica,

11 Exemplo extraído de Mateus et alii (2003).

12 Designação de Demonte (1999: 139). Não confundir com a classe de "quantificadores" definida por Mateus et alii (2003) (muito, pouco, tanto, etc.) que no conceito desta autora fica fora da categoria dos adjetivos.

13 Bechara (2001: 584) 
psicológica. O maior responsável pela ordem favorita numa língua ougrupo de línguas parece ser a entonação oracional."

Bechara ainda lembra que "o adjetivo monossilábico modificador precede o nome de maior extensão fonética: bom dia, má hora, etc.” Observando rigorosamente a lógica, acrescentamos que a extensão fonética do nome pode também ser igual à do adjetivo (não só maior), caso ambos sejam monossilábicos: bom fim, bom pau, mau pão (e normalmente não fim bom, pau bom, pão mau).

Resumindo as diversas abordagens: encontramos uma abordagem enumerativa, uma sugestão de existência dos "grupos fraseológicos tópicos", uma defesa de influências fonéticas e uma sistematização à base semântica. Agora vem propriamente o ponto, em que convém servir-se do corpus e verificar todas estas hipóteses.

\section{Análise empírica dos aspetos da colocação}

\subsection{Observações aos aspetos semânticos}

Os aspetos semânticos são os mais abundantes, os mais complicados e, ao mesmo tempo, os mais influentes de todos os aspetos linguísticos da colocação do adjetivo. Ao mesmo tempo são também os mais debatidos e enfatizados pela generalidade linguística e já foram parcialmente expostos nos capítulos anteriores. Será justamente por esta causa que apresentaremos só algumas observações, as mais interessantes e fáceis de expor.

Se já abordámos o valor da inerência transmitido pelo adjetivo anteposto, permitimo-nos agora demonstrar o paralelismo linguístico entre a anteposição/posposição e inerência/transitoriedade através dos verbos ser e estar. Repare-se que numa situação predicativa usamos o verbo ser para marcar a inerência, enquanto o verbo estar exprime um estado transitório. ${ }^{14}$ Os mesmos efeitos obtêm-se pela devida colocação, quando a posição não é predicativa. Compare-se:

- o quente sol - o sol é quente; o sol está quente* 15

- o bolo quente - o bolo está quente

- ${ }^{*}$ o quente bolo $-{ }^{\star}$ o bolo é quente

No que diz respeito ao valor figurado ou expressivo, estes são atingidos através do uso dum adjetivo normalmente incompatível com a posição pré-nominal (cumprindo sobretudo os relacionais com esta condição). Tal adjetivo, quando anteposto, perde a parte restritiva do seu significado, permanecendo-lhe as restantes componentes semânticas. Este sentido reduzido pode geralmente ser expresso por outro adjetivo sinonímico, que porém careceria da marcação, figuração e expressividade:

14 Nas palavras de Casteleiro (1989: 36-37, in Callou et alii (2002: 3)), os adjetivos "na posição pós-nominal implicam de certo modo atribuição contingente ou temporária. Na posição pré-nominal, pelo contrário, supõem atribuição constante ou típica."

15 Obviamente é também possível pospor o adjetivo, embora a característica expressa seja inerente ao denotado do substantivo, quando se pretende não acentuar essa inerência: o sol quente - o sol é quente. 
- Sentiu no coração uma quase má vontade contra o nocturno visitador.16 [noturno $\approx$ importuno]

Queremos também chamar a atenção à oscilação de certos adjetivos que flutuam entre as classes de qualificativos e relacionais. Tendo normalmente um sentido qualificativo, em algumas situações, tais adjetivos podem exprimir um valor restritivo (geralmente quando entram numa oposição contextual): água fria / água quente. Nestes casos, a anteposição é sempre agramatical: ${ }^{\star}$ fria água / ${ }^{\star}$ quente água. Sem a oposição contextual (ou seja: quando é retirado o valor restritivo), o mesmo sintagma pode ser gramatical: a fria água [do Atlântico]. Vemos portanto que o contexto e o carácter pragmático da comunicação têm o seu papel importante na perceção da gramaticalidade da anteposição do adjetivo.

Finalmente, reparemos ainda nos casos de sintagmas nominais com mais que um adjetivo. Apesar de termos registado diversos "mitos gramaticais" acerca destes casos, a nossa pesquisa mostrou que a presença de outro adjetivo pouco interfere com a posição do adjetivo em questão. Os fatores semânticos mantêm o seu vigor - adjetivos relacionais são pospostos, a posição dos adjetivos qualificativos segue os padrões acima abordados. Convém só observar que a relação entre o substantivo e um adjetivo relacional, dado que constituem uma unidade semântica, é mais forte do que a relação entre o substantivo e um adjetivo qualificativo. Havendo um adjetivo qualificativo e um relacional, o adjetivo qualificativo portanto oscila à volta deste mencionado "núcleo semântico":

- deselegante carro amarelo, carro amarelo deselegante

Em caso de dois adjetivos relacionais ocorre uma dupla posposição. A ordem dos adjetivos pospostos é obviamente dependente da força restritiva do dado adjetivo (o adjetivo com maior força restritiva estará posicionado mais perto do substantivo):

- linhas aéreas portuguesas, ${ }^{*}$ linhas portuguesas aéreas

Em caso de dois adjetivos qualificativos, ao contrário, o posicionamento é bastante livre e, outra vez, obedece aos princípios semãnticos esclarecidos acima, mas também a outros, não semânticos, que virão a ser apresentados. Svobodová (2014: 109) porém fala a respeito destes casos sobre o relacionamento entre o simetrismo e o (não-)sindetismo destes sintagmas:

- jovem mulher magra, magra mulher jovem

- mulher magra e jovem, magra e jovem mulher

\subsection{Aspetos fraseológicos}

$\mathrm{Na}$ análise das gramáticas aludimos às expressões cristalizadas, ou seja grupos fraseológicos tópicos. Vázquez Cuesta (1989) considera-os uma das causas ou motivos de anteposição de adjetivos, que nessa posição "perdem um pouco do seu valor". A autora não especifica mais o termo 
"grupo fraseológico tópico", mas deduz-se que esses grupos têm um valor fraseológico em termos de certa remodelação do sentido, tanto como um carácter tópico, formando combinações típicas (tópicas) de substantivos com adjetivos antepostos.

Com a nossa pesquisa, chegámos a confirmar que muitos dos adjetivos qualificativos antepostos realmente formam com os substantivos os "grupos fraseológicos tópicos" sugeridos por esta autora. O termo usado, porém, não necessariamente denota o que geralmente entendemos sob "expressoões idiomáticas" - trata-se duma unidade fraseológica primordialmente destacada pela estabilidade formal e menos, talvez muito menos pela mudança do valor semântico. O fenómeno da cristalização do adjetivo anteposto portanto não se observa em expressoões verdadeiramente idiomáticas como p. ex. "fazer castelos no ar", mas sim em expressões "[ser de] fresca data" ou "[ter um] triste fim", onde os valores semânticos dos termos componentes se mantêm quase intactos. Apesar disso, podemos observar diversas semelhanças entre os dois conceitos. Por exemplo, ambos estes fenómenos linguísticos podem servir para acrescentar um valor estilístico (reforço, expressividade) ao ato locutório. Um olhar detalhado para os resultados revela ainda outros traços de cristalização (ora mais, ora menos significativos), entre os quais se destacam:

- a preservação do número (plural ou singular) em algumas das combinações: plenos pulmões / *pleno pulmão; fresca data / ${ }^{*}$ frescas datas; $\left({ }^{*}\right.$ fazer [um] castelo no ar); ${ }^{17}$

- a necessidade de incorporação sintática, p. ex. num sintagma preposicional: [uma mudança] de fresca data

Os resultados das consultas ao corpus revelam muitas combinações que não permitem a posposição do adjetivo:

- baixo ventre, ${ }^{*}$ ventre baixo; doce paz, ${ }^{\star}$ paz doce; plenos pulmões, ${ }^{*}$ pulmões plenos; puro engano, *engano puro

Nestes casos, uma posposição já se encontra na fronteira entre agramaticalidade, falta de sentido ou um disparate estilístico. Obviamente, uma posposição é em certos casos admissível, mas com um adjetivo sinónimo que quebra o fenómeno da cristalização. Assim confirma-se novamente o carácter cristalizado das expressões acima:

- doce paz $\approx$ paz solene

- puro engano $\approx$ engano profundo, engano fatal

As causas da cristalização, além de certa "consagração pelo uso", podem (em alguns casos) ser diversas. Como justificaremos no próximo capítulo, a configuração "paz doce” apresenta certa incompatibilidade fonética (justaposição de sílabas tónicas) que condiciona a anteposição do adjetivo; no ditado "ruim senhor cria ruim servidor", a posposição provocaria uma justaposição

17 Referimo-nos ao significado generalizado sem contexto. Obviamente, as formas indicadas como erradas são justificáveis se o referente tem só um pulmão ou está a elaborar um projeto megalómano, e em tal caso, o número normalmente agramatical fornece uma marcação especial às expressões. 
desagradável das consoantes [r] e [R]. Assim, queremos destacar que as causas da cristalização podem ser, além da «consagração do uso», também de ordem fonética.

Outra causa possível da cristalização é o relacionamento lexical estreito que vigora em algumas combinações, onde não ocorre propriamente uma transformação de significados dos constituintes. Muitas vezes trata-se de termos técnicos jurídicos, médicos, técnicos ou de conceitos únicos. O adjetivo aparece fora da sua posição não marcada e assume uma função especificadora, não qualificadora. Repare-se:

\section{- legítima defesa; justa causa; baixo ventre; Imaculada Conceição; Sagrada Família}

Afinal, o uso de certas expressões cristalizadas específicas tornou-se domínio de alguns autores literários. Há autores que criaram os seus próprios grupos “fraseológicos tópicos”, marcados justamente pela anteposição. Estes são difíceis de descobrir, mas como um bom exemplo podemos apresentar a Almeida Garrett com a expressão "vil prosa” (exemplos extraídos do corpus). Nenhum outro autor representado no corpus usou esta expressão, enquanto Garrett a usou várias vezes:

- [...] este digno filho de Apollo se abaixa á ${ }^{18}$ vil prosa, [...] (Lírica, 1829)

- Mas emfim é vil prosa, indigna do sesquipedal imitador de Stacio,[...] (Lírica, 1829)

- Mas..mas passemos á vil prosa dos interêsses materiaes do paiz, se é preciso. (Falar verdade a mentir, 1845) [...]

- [...] no mais acrisolado afecto do homem que não é poeta, entra sempre o seu tanto da vil prosa humana: [...] (Viagens na minha terra, 1846)

\subsection{Aspetos prosódicos e fonéticos}

Voltaremos à afirmação de Bechara (2001), que acentua o papel do ritmo da fala na colocação do adjetivo dizendo que "a colocação [...] obedece a tendências variadas, quer de ordem restritamente gramatical, quer de ordem rítmica, psicológica"19.

Para demonstrar a importância do ritmo, escolhemos como um exemplo adequado o adjetivo leve. Uma simples consulta do corpus revela que em posposição, este adjetivo combina quase exclusivamente com substantivos paroxítonos e monossilábicos (som, sol, voz, ar, pé entre outros). Ao contrário, com os substantivos oxítonos polissilábicos (tremor, rubor, rumor, sensação, pressão), leve ocorre quase sempre anteposto. Isto leva-nos forçosamente à convicção de que o ritmo influi significativamente na decisão sobre a colocação deste adjetivo. Concretamente, esta situação sugere que existe um esforço para evitar a justaposição de duas sílabas tónicas (como seria o caso em "pressão leve, rumor leve"). A nossa pesquisa revelou que é possível generalizar esta revelação. Caso um dos nomes observados comece ou acabe numa sílaba tónica, os falantes tendem a mantê-la separada de outra sílaba tónica, ou seja,

18 A contração de preposição com artigo aparece aqui com acento agudo em conformidade com a grafia do original.

19 Bechara (2001: 581). 
tendem a rodeá-la de sílabas átonas. E neste processo prescindem da distinção rigorosa das classes lexicais, tanto como da obediência a certas regras gramaticais. Para estender e fortificar a validade destas nossas afirmações, podemos ainda demonstrar o mesmo brevemente com adjetivos trissilábicos ${ }^{20}$. Os resultados estão em acordo com as afirmações anteriores:

- sempre trémulo pé, trémulo pudim, trémulo coração e nunca pé trémulo, pudim trémulo, coração trémulo

- geralmente íntima comoção, intima conexão, raramente comoção intima, conexão intima

- enquanto:

- sempre gente folgazã, nunca folgazã gente; mas folgazãs desculpas ao lado de desculpas folgazãs.

Dediquemo-nos ainda brevemente aos adjetivos monossilábicos, porque o comportamento deles é bastante particular. Uma vez que representam uma sílaba tónica isolada e prestes a deslocar-se facilmente, o papel decisivo é trespassado para o substantivo e a sua configuração silábica. A colocação do adjetivo depende aqui do substantivo - ao contrário do que normalmente é constatado pelas gramáticas ${ }^{21}$.

Para evitar uma possível aberração da prova, decidimos excluir os adjetivos bom, mau, só, cujas propriedades semânticas são demasiadamente peculiares e não garantem uma manifestação suficientemente pronunciada dos fatores prosódicos. Aliás, um estudo parcialmente dedicado à colocação destes adjetivos foi já efetuado por Hricsina (2013). Os seus resultados não contradizem os nossos, mas a sua pesquisa não foi suficientemente profunda para poder constituir uma confimação.

Poucos são então os adjetivos monossilábicos que restam para observar: usaremos os adjetivos «são, vão, vil».

- sempre sã virtude, sã verdade, sã razão, sã lição e nunca razão sã, lição sãa; sempre carne sã, arte sã, alma sã; nunca sã carne, sã alma, sã arte; mente sã em corpo são.

- sempre vã mentira, vão desejo, vãs palavras, vão amor, vão desdém e nunca amor vão, desdém vão; sempre coisas vãs, almas vãs, arte vã, pressa vã, luta vã e nunca vãs coisas, vãs almas, vã luta.

- geralmente mundo vil, homem vil, sangue vil, alma vil, carne vil, peito vil e não vil mundo, vil homem, vil peito etc.; geralmente vil animal, vil metal, vil mulher e não animal vil, metal vil, mulher vil.

Confirma-se aqui que também o adjetivo monossilábico evita ser colocado ao lado duma sílaba tónica. Assim, a posposição predomina com substantivos paroxítonos, enquanto a anteposição prevalece com substantivos oxítonos (desde que sejam dissilábicos).

Além da questão da sílaba tónica, consideramos ainda importante advertir que a nível fonético existe também uma tendência para evitar, na fronteira entre as palavras, a justaposição de grupos sónicos semelhantes:

20 Podemos tranquilamente evitar os adjetivos trissilábicos paroxítonos, cuja sílaba tónica já está rodeada de sílabas átonas e perde assim qualquer influência na colocação do adjetivo.

21 Esta nossa verificação entra, primordialmente, em conflito com o próprio Bechara (2001: 584), que afirma que "o adjetivo monossilábico modificador precede o nome de maior extensão fonética." Enquanto este autor se serve dos exemplos bom e mau (e teria razão se fossem os únicos adjetivos monossilábicos existentes), nós decidimos evitá-los e chegámos a resultados bem diferentes. 
- audaz capitão e não capitão audaz; alma vã e não vã alma

- ruim senhor cria ruim servidor e não senhor ruim cria servidor ruim

Das pesquisas acima descritas podemos então concluir que certos aspetos fonéticos (sobretudo a configuração acentual) influem não prescindivelmente na colocação do adjetivo, mas são forçosamente subordinados a aspetos semânticos, sintáticos e até lexicais. ${ }^{22}$ Permitindo estes alguma variabilidade da colocação, o lado fonético das palavras pode também exercer o seu papel na decisão final sobre a posição do adjetivo. A sua força é portanto bastante restrita.

De qualquer maneira, é necessário entender a sílaba tónica como uma zona de contacto e interação fonética. Na fronteira entre as palavras, esta sílaba comporta-se como uma espécie de íman com dois polos, que (a não ser aplicada força externa) só atrai outros ímanes quando estes lhe expõem o seu lado oposto (sílaba átona). Quando os polos se repelem, a sua ordem tende a mudar, dentro de limites impostos do exterior.

\subsection{Aspetos de ordem sintática}

Do ponto de vista sintático, os constituintes que mais influem na colocação do adjetivo são os complementos do adjetivo e expressões comparativas. Dada a estrutura geral dum sintagma adjetival: "quantificador + adjetivo (núcleo) + complemento do adjetivo + expressão comparativa”, é necessário observar que o primeiro e último nunca são obrigatórios, enquanto o complemento pode ser obrigatório ou facultativo:

\section{- uma criança ansiosa / uma ansiosa criança / uma criança ansiosa por férias}

Das nossas pesquisas ressaem principalmente estes três factos:

a) a presença dum complemento ou duma expressão comparativa não permite a anteposição dum adjetivo, que sem eles poderia estar anteposto: ${ }^{23}$

- um esperto rapaz / um rapaz (tão) esperto como uma lebre / ${ }^{*}$ um ( ${ }^{*}$ tão) esperto rapaz ( ${ }^{*}$ tanto) como uma lebre,

- um digno livro / um livro digno - um livro digno de confiança / *um digno de confiança livro / *um digno livro de confiança,

- uma criança ansiosa por férias / *uma ansiosa criança por férias;

b) esta limitação, no entanto, não vale para o potencial quantificador, que precede o adjetivo: um imensamente feio prédio, uma muito piedosa mulher.

22 Repetimos que tem que tratar-se dum adjetivo qualificativo, nunca dum relacional. Entre os aspetos sintáticos contamos outros constituintes do sintagma nominal ou do sintagma adjetival subordinado, que possam impedir a colocação em uma ou outra posição. Os aspetos lexicais incluem p. ex. a cristalização ou grau de proximidade (trata-se de duas palavras simples ou de uma palavra composta?).

23 Complementos de adjetivo costumam naturalmente acompanhar adjetivos relacionais (denominais, deverbais), retomando a sua estrutura (sobretudo a preposição) do respetivo substantivo ou verbo. Poucos dos adjetivos qualificativos podem ser acompanhados por complementos, mas existem - vejam-se os exemplos. 
A obrigatoriedade do complemento pode impedir a anteposição, embora o complemento esteja supresso, subentendido. É o caso de cheio no seguinte exemplo:

- uma chávena cheia [de leite] / *uma cheia [de leite] chávena

\section{Conclusão}

Dito o dito, resta resumir os resultados, tirar conclusões e tomar atitudes. Principalmente podemos constatar que foram confirmadas quase todas as afirmações das gramáticas, mas é necessário lembrar que nenhuma delas ofereceu uma abordagem integral do problema. Vimos que a realidade se encontra algures no meio entre os diversos pontos de partidas dessas gramáticas, tomando cada uma a sua postura firme perante o problema.

Os aspetos semânticos, os mais óbvios, são também os mais enfatizados em todas as gramáticas. A anteposição tem-se revelado como um meio de intensificação do significado e de modificação arbitrária do sentido, mas também pode atribuir um valor de inerência a um adjetivo qualificativo ou de expressividade, se o adjetivo é relacional. No âmbito dos aspetos fraseológicos confirmou-se a hipótese de que em muitos casos os adjetivos antepostos fazem parte de expressões mais ou menos cristalizadas, sendo que as causas da cristalização oscilam entre os lados propriamente fraseológico (quando há uma transformação semântica), fonético e subjetivo. No campo da sintaxe identificámos a presença de complementos e expressões comparativas como provavelmente o único fator significativo que pode influenciar a colocação do adjetivo.

No entanto, de forma inesperada, foram identificadas fortes influências fonéticas à colocação do adjetivo. A nível fonético, o adjetivo interage com o substantivo e é colocado de forma para evitar a justaposição de sílabas tónicas. Sendo assim, as implicações fonéticas são válidas só para tais substantivos e adjetivos, que começam ou acabam com uma sílaba tónica. Ao mesmo tempo, os adjetivos antepostos, quando o são devido a causas fonéticas, perdem grande parte da marcação e das especialidades semânticas normalmente proporcionadas por ela. O lado semântico também decide sobre o vigor destas regras fonéticas - os adjetivos relacionais geralmente impedem a sua aplicação.

Do dito ressai que as diversas influências, por um lado, obedecem a uma certa hierarquia - com os fatores semânticos como primordiais, seguidos pelos sintáticos, fraseológicos e fonéticos. Por outro lado, esta hierarquia não é sempre fixa. O peso atribuído aos fatores, num determinado caso, reflete-se na decisão final sobre a colocação do adjetivo. Estes pesos, somando-se e subtraindo-se mutuamente, conduzem cada caso a um resultado mais ou menos particular. Isso obviamente torna difícil a identificação e verificação de quaisquer regras ou influências; ainda assim, acreditamos ter conseguido, de modo bastante persuasivo, captar os pontos mais relevantes da problemática. 


\section{Referências bibliográficas}

Bechara, E. (2001). Moderna gramática portuguesa. Rio de Janeiro: Lucerna.

Bosque, I., \& Demonte, V. (dirs.) (1999). Gramática descriptiva de la lengua española: Sintaxis básica de las clases de palabras. Madrid: Espasa.

Buda, J. (2010). As Lacunas da Ortografia Portuguesa. Brno: Masarykova univerzita.

Callou, D., et alii (2002). A posição do adjetivo no sintagma nominal: duas perspectivas de análise. Acessível online a partir de: <http://www.clul.ulisboa.pt/equipa/fbacelar/ufrj_2002_nascimento_etal.pdf>

Casteleiro, J. M. (1981). Sintaxe Transformacional do Adjectivo. Lisboa: INIC.

Cunha, C., \& Lindley Cintra, L. F. (2006). Breve gramática de português contemporâneo. Lisboa: Edições João Sá da Costa.

Davies, M., \& Ferreira, M. (2006). Corpus do Português: 45 million words, 1300s-1900s. Acessível online a partir de <http://www.corporadoportugues.org >

Hampl, Z. (1972). Stručná mluvnice portugalštiny. Praha: Academia.

Hricsina, J. (2013). A posição do adjetivo no sintagma nominal no português contemporâneo: Análise corporal. Romanistica Pragensia, 19, 203-218.

Mira Mateus, M. H., et alii (2003). Gramática da língua portuguesa. Lisboa: Editorial Caminho.

Svobodová, I. (2014). Morfologie současného portugalského jazyka I. Brno: Masarykova Univerzita.

Vázquez Cuesta, P., \& Mendes da Luz, M. A. (1989). Gramática da língua portuguesa. Lousã: Tipografia Lousanense.

\section{Anexos}

Anexo 1: Tabela das ocorrências de anteposição e posposição dos 45 adjetivos mais frequentes na ficção de Portugal e do Brasil nos séculos XIX e XX.

\begin{tabular}{|c|c|c|c|c|c|c|}
\hline adjetivo & $\begin{array}{l}\text { ocorrências } \\
\text { em total }\end{array}$ & $\begin{array}{c}\text { oc. em } \\
\text { sintagma } \\
\text { nominal }\end{array}$ & $\begin{array}{c}\text { ante- } \\
\text { posicões }\end{array}$ & $\begin{array}{c}\text { pos- } \\
\text { posições }\end{array}$ & a./p. & $\begin{array}{c}\text { a./p. } \\
\text { logaritmizado (10) }\end{array}$ \\
\hline outro & 19724 & 5254 & 5101 & 153 & 33,34 & 1,52 \\
\hline mesmo & 13418 & 2818 & 2614 & 204 & 12,81 & 1,11 \\
\hline bom & 6165 & 2095 & 1786 & 309 & 5,78 & 0,76 \\
\hline grande & 7468 & 2067 & 1450 & 617 & 2,35 & 0,37 \\
\hline certo & 3474 & 1401 & 1185 & 216 & 5,49 & 0,74 \\
\hline novo & 5737 & 1242 & 540 & 702 & 0,77 & $-0,11$ \\
\hline próprio & 3622 & 1210 & 978 & 232 & 4,22 & 0,62 \\
\hline último & 1629 & 1118 & 1095 & 23 & 47,61 & 1,68 \\
\hline velho & 7555 & 1084 & 627 & 457 & 1,37 & 0,14 \\
\hline seguinte & 1176 & 1065 & 72 & 993 & 0,07 & $-1,14$ \\
\hline alto & 3983 & 1049 & 379 & 670 & 0,57 & $-0,25$ \\
\hline
\end{tabular}




\begin{tabular}{|c|c|c|c|c|c|c|}
\hline adjetivo & $\begin{array}{c}\text { ocorrências } \\
\text { em total }\end{array}$ & $\begin{array}{c}\text { oc. em } \\
\text { sintagma } \\
\text { nominal }\end{array}$ & $\begin{array}{c}\text { ante- } \\
\text { posicões }\end{array}$ & $\begin{array}{c}\text { pos- } \\
\text { posições }\end{array}$ & a. $/ \mathbf{p}$. & $\begin{array}{c}\text { a./p. } \\
\text { logaritmizado (10) }\end{array}$ \\
\hline mau & 1623 & 924 & 763 & 161 & 4,74 & 0,68 \\
\hline tal & 3189 & 893 & 783 & 110 & 7,12 & 0,85 \\
\hline pequeno & 2790 & 871 & 596 & 275 & 2,17 & 0,34 \\
\hline único & 1290 & 865 & 678 & 187 & 3,63 & 0,56 \\
\hline aberto & 1500 & 846 & 24 & 822 & 0,03 & $-1,53$ \\
\hline maior & 2148 & 805 & 561 & 244 & 2,30 & 0,36 \\
\hline negro & 3516 & 740 & 147 & 593 & 0,25 & $-0,61$ \\
\hline pobre & 2462 & 739 & 560 & 179 & 3,13 & 0,50 \\
\hline inteiro & 1017 & 717 & 21 & 696 & 0,03 & $-1,52$ \\
\hline longo & 1757 & 704 & 521 & 183 & 2,85 & 0,45 \\
\hline belo & 1298 & 695 & 633 & 62 & 10,21 & 1,01 \\
\hline melhor & 3306 & 570 & 379 & 191 & 1,98 & 0,30 \\
\hline verde & 1339 & 543 & 48 & 495 & 0,10 & $-1,01$ \\
\hline antigo & 1566 & 512 & 273 & 239 & 1,14 & 0,06 \\
\hline azul & 1274 & 512 & 21 & 491 & 0,04 & $-1,37$ \\
\hline cheio & 2531 & 502 & 1 & 501 & 0,00 & $-2,70$ \\
\hline vermelho & 1233 & 480 & 11 & 469 & 0,02 & $-1,63$ \\
\hline forte & 1881 & 472 & 148 & 324 & 0,46 & $-0,34$ \\
\hline estranho & 1561 & 470 & 177 & 293 & 0,60 & $-0,22$ \\
\hline fino & 1050 & 467 & 124 & 343 & 0,36 & $-0,44$ \\
\hline humano & 1098 & 459 & 18 & 441 & 0,04 & $-1,39$ \\
\hline claro & 2551 & 449 & 70 & 379 & 0,18 & $-0,73$ \\
\hline simples & 1178 & 425 & 250 & 175 & 1,43 & 0,15 \\
\hline escuro & 1344 & 419 & 37 & 382 & 0,10 & $-1,01$ \\
\hline enorme & 1105 & 418 & 184 & 234 & 0,79 & $-0,10$ \\
\hline triste & 1474 & 396 & 141 & 255 & 0,55 & $-0,26$ \\
\hline rico & 1227 & 391 & 122 & 269 & 0,45 & $-0,34$ \\
\hline bonito & 1269 & 384 & 101 & 283 & 0,36 & $-0,45$ \\
\hline morto & 2197 & 362 & 14 & 348 & 0,04 & $-1,40$ \\
\hline baixo & 1703 & 344 & 63 & 281 & 0,22 & $-0,65$ \\
\hline vivo & 1382 & 334 & 84 & 250 & 0,34 & $-0,47$ \\
\hline feliz & 1145 & 232 & 56 & 176 & 0,32 & $-0,50$ \\
\hline possível & 1364 & 211 & 88 & 123 & 0,72 & $-0,15$ \\
\hline capaz & 1321 & 132 & 2 & 130 & 0,02 & $-1,81$ \\
\hline
\end{tabular}


Anexo 2: Expressões cristalizadas com adjetivo anteposto

( $\mathrm{A}, \mathrm{P}=$ número de occorrências em anteposição/posposição)

\begin{tabular}{|c|c|c|c|c|c|c|c|}
\hline adjetivo & substantivo & a & p & adjetivo & substantivo & a & $\mathbf{p}$ \\
\hline \multirow[t]{3}{*}{ velho } & tempos & 97 & 0 & verdadeiro & amor & 14 & 4 \\
\hline & amigos & 13 & 3 & & paixão & 9 & 0 \\
\hline & & & & & nome ${ }^{*}$ & 8 & 11 \\
\hline \multirow[t]{3}{*}{ grande } & parte & 91 & 0 & & & & \\
\hline & olhos & 76 & 35 & livre & vontade & 13 & 0 \\
\hline & silêncio & 49 & 5 & & arbítrio & 5 & 0 \\
\hline \multirow[t]{4}{*}{ bom } & jesus & 162 & 0 & leve & sorriso & 7 & 0 \\
\hline & vontade & 79 & 1 & & rubor & 5 & 0 \\
\hline & senso & 60 & 0 & & & & \\
\hline & & & & sério & problemas & 5 & 0 \\
\hline \multirow[t]{4}{*}{ novo } & vida & 32 & 46 & natural & confusão & 5 & 0 \\
\hline & mundo & 24 & 26 & & & & \\
\hline & dia & 23 & 2 & rápido & olhares & 7 & 0 \\
\hline & & & & & visão & 4 & 0 \\
\hline \multirow[t]{5}{*}{ alto } & noite & 39 & 29 & raro & vezes & 49 & 0 \\
\hline & horas & 37 & 2 & & pessoas & 5 & 0 \\
\hline & sociedade & 9 & 0 & & & & \\
\hline & & & & duro & penas & 5 & 0 \\
\hline & & & & & existência & 2 & 0 \\
\hline \multirow[t]{3}{*}{ pequeno } & coisas & 22 & 2 & & & & \\
\hline & mesa & 19 & 4 & profundo & suspiro & 6 & 6 \\
\hline & nadas & 16 & 0 & & tristeza $^{*}$ & 4 & 17 \\
\hline \multirow[t]{3}{*}{ claro } & sol & 5 & 3 & puro & verdade & 10 & 18 \\
\hline & $\operatorname{luz} z^{*}$ & 5 & 16 & & perda & 9 & 0 \\
\hline & & & & & engano & 8 & 0 \\
\hline \multirow[t]{3}{*}{ pobre } & diabo & 27 & 0 & & & & \\
\hline & alma & 11 & 0 & louco & vontade & 3 & 0 \\
\hline & coitado & 8 & 0 & & & & \\
\hline
\end{tabular}




\begin{tabular}{|c|c|c|c|c|c|c|c|}
\hline adjetivo & substantivo & $\mathbf{a}$ & $\mathbf{p}$ & adjetivo & substantivo & $\mathbf{a}$ & p \\
\hline & & & & curto & silêncio & 17 & 0 \\
\hline preciso & momento & 6 & 5 & & prazo & 9 & 0 \\
\hline & instante & 6 & 3 & & distância & 8 & 0 \\
\hline forte & cheiro & 6 & 19 & fresco & data & 4 & 0 \\
\hline & impressão & 5 & 0 & & & & \\
\hline & dor & 3 & 1 & pálido & raios & 4 & 0 \\
\hline longo & tempo & 59 & 4 & lindo & olhos & 9 & 6 \\
\hline & viagem & 16 & 3 & & dia & 6 & 6 \\
\hline & conversa & 10 & 1 & & cabelos & 5 & 0 \\
\hline baixo & preço & 5 & 2 & doce & paz & 4 & 0 \\
\hline & ventre & 3 & 1 & & nome & 4 & 0 \\
\hline & & & & & ilusão & 3 & 0 \\
\hline mau & humor & 50 & 0 & & & & \\
\hline & vontade & 45 & 0 & firme & propósito $^{*}$ & 5 & 5 \\
\hline & gosto & 42 & 0 & & resolução & 3 & 8 \\
\hline antigo & companheiro & 8 & 0 & comum & acordo & 3 & 0 \\
\hline & colega & 9 & 0 & & & & \\
\hline & namorada & 5 & 0 & comprido & mesa & 4 & 0 \\
\hline estranho & caso & 9 & 4 & justo & direito & 4 & 0 \\
\hline & sensação & 7 & 5 & & & & \\
\hline & morte & 4 & 0 & terrível & ameaça & 2 & 0 \\
\hline triste & fim & 7 & 0 & nobre & senhor & 17 & 0 \\
\hline & figura & 7 & 0 & & & & \\
\hline & notícia & 4 & 0 & eterno & sombra & 7 & 0 \\
\hline & & & & & problema & 3 & 0 \\
\hline vivo & força & 8 & 4 & & & & \\
\hline & alma* & 4 & 6 & doloroso & experiência* & 4 & 6 \\
\hline & cores $^{*}$ & 4 & 18 & & & & \\
\hline
\end{tabular}




\begin{tabular}{|c|c|c|c|c|c|c|c|}
\hline adjetivo & substantivo & a & p & adjetivo & substantivo & $\mathbf{a}$ & $\mathbf{p}$ \\
\hline & & & & suave & melancolia & 5 & 0 \\
\hline verde & anos & 7 & 0 & & declive & 4 & 3 \\
\hline \multirow[t]{4}{*}{ belo } & dia & 46 & 0 & pleno & pulmões & 17 & 0 \\
\hline & olhos & 18 & 0 & & dia & 11 & 0 \\
\hline & figura & 12 & 0 & & rua & 9 & 0 \\
\hline & & & & & consciência & 6 & 0 \\
\hline \multirow[t]{4}{*}{ simples } & facto & 12 & 0 & & & & \\
\hline & palavra & 10 & 0 & surdo & hostilidade & 4 & 0 \\
\hline & razão & 6 & 0 & & rumor & 4 & 7 \\
\hline & & & & & raiva & 2 & 0 \\
\hline \multirow[t]{2}{*}{ feliz } & aniversário & 2 & 0 & & & & \\
\hline & marido & 3 & 0 & violento & esforço & 3 & 4 \\
\hline \multirow[t]{3}{*}{ enorme } & esforço & 8 & 4 & cruel & destino & 4 & 0 \\
\hline & desejo $^{*}$ & 4 & 7 & & & & \\
\hline & & & & divino & providência & 16 & 4 \\
\hline \multirow[t]{3}{*}{ fino } & força & 6 & 0 & & espírito & 7 & 1 \\
\hline & trato & 3 & 0 & & & & \\
\hline & sabor & 3 & 0 & & & & \\
\hline
\end{tabular}


